\title{
An Investigation of Characteristics Affecting Employment Outcomes and Patterns of Real Estate Graduates
}

\section{Structured Abstract:}

\section{Purpose}

The aim of this research is to develop a comprehensive picture of characteristics affecting the employment outcomes and patterns for real estate graduates in Australia. Furthermore, this paper benchmarks the characteristics affecting employment prospects of real estate graduates against those of built environment graduates.

\section{Design/methodology/approach}

The data used in this paper were collected by the Australian Graduate Survey (AGS). Dimensionality reduction was used to prepare the dataset for the courses listed in the AGS data, in order to develop the simplified classifications of courses used to conduct the analysis in this paper. Dimensionality reduction was also used to prepare the dataset for the analysis of the employment outcomes and patterns for real estate and built environment graduates. Descriptive and statistical analysis methods were used to identify the difference in characteristics, such as gender, age, attendance type, mode of study, degree levels and English proficiency, for real estate and built environment graduates, the level of the influence of these characteristics on their employment outcomes and patterns and the statistical relationship between individual characteristics and employment outcomes as well as employment patterns of the graduates.

\section{Findings}

English proficiency was found to be an important factor for real estate and built environment graduates for securing employment and it has a statistically significant impact on the employment outcomes and patterns for the graduates. Despite the fact that age and attendance type have no statistical impact on employment outcomes for real estate and built environment graduates, they were found to have statistical significant impact on their employment patterns.

\section{Originality/value}

This is pioneering research which used official government data, such as AGS data, to provide a reliable and thorough picture of the employment outcomes and patterns for real estate and built environment graduates.

\section{Keywords:}

Australian Graduate Survey (AGS), Characteristics, Employment Outcomes and Patterns, Graduates, Real Estate

\section{Article Classification:}

Research paper 


\section{Introduction}

'Given the substantial public investment in university students, it is particularly important that they are employable upon graduation. Better information is crucial to this aim. Work is already in progress on improving performance indicators, including those on employment outcomes that will better inform the choice of prospective students. Those relating to employment outcomes will take effect in 2000.'

(Rt. Hon. Gordon Brown, Chancellor of Exchequer, cited in PISG, HEFCE Report 99/11, February

Australia was less affected by the global financial crisis of $2007 / 2008$ than other major economies. The unemployment rate in Australia is lower than most other developed countries. The Australian government, in much the same way as the UK government, has given much attention to the higher education sector, along with investment, to encourage students from disadvantaged backgrounds to attend university (Bradley Report, 2008). The government has also given serious consideration to employment (DEST, ACCI and BCA, 2002; DIICCSRT, DEEWR and CSfW, 2013; Precision Consultancy, 2007). Gaining employment is considered a key factor in measuring the success of a university degree level education. Therefore, there is a need to examine the important characteristics that enhance a graduate's employment prospects.

'Finding a job', becoming employable and embarking on a career have also become important criteria for the students' choice of institution and course (Rae, 2007). Rae (2007) commented that potential university applicants have been increasingly realising that simply having a degree is not sufficient to secure a job after graduation. They require other attributes in order to become employable. As a result, graduate employment has been considered as one of the characteristics for the potential applicants to base their decision on the course and institution they choose to attend. Therefore, universities have become more proactive in featuring employability as a factor in their 'offer' whilst potential applicants are likely to be influenced by league tables and student satisfaction surveys; employment outcomes are key criteria in both.

\section{Characteristics which affect graduate employment}

Gender is one of the most influential demographic characteristics on graduate employment (Artess et al., 2008; McKnight, 1999). McKnight (1999) reported on the result of a survey of approximately 11,000 graduates in 1995 from 33 higher education institutions in the UK, tracking their early career paths over the first three and a half years. The results suggested that gender is one of the characteristics affecting graduates' early career trajectories. The findings of Smith et al.'s (2000) analysis of official data for First Destination Survey (FDS), conducted by Careers Offices of each university and deposited with the Higher Education Statistics Agency (HESA) in the UK also shared the same finding. Elias et al. (1999) and Smith et al. (2000) found that more male graduate leavers were unemployed but at the same time a higher proportion of them worked in graduate level occupations. Similar patterns were also reported for postgraduate leavers by Artess et al. (2008). Artess et al. (2008) and Elias et al. (1999) also found that male graduates usually have a favourable salary difference as compared to female graduates. Dainty et al. (2000) investigated women's employment opportunities and career progression patterns in large construction companies. They concluded that men and women experienced disparate career progression dynamics. Women were found to have a slower progression rate and have a greater number of obstacles to their professional development. The employment patterns of men and women also differed, with $92 \%$ of men being employed in full-time positions compared with only $55 \%$ of women. Furthermore, there are also more women employed in part-time positions than men at $43 \%$ and $2 \%$ respectively (IER, 1997). Fielden et al. (2000) identified the sources of barriers hindering women from having as successful a career as their male colleagues, such as the construction industry's image; career knowledge amongst children and adults; selection criteria and male dominated courses; recruitment 
practices and procedures; sexist attitudes; male dominated culture; and the work environment. Fielden et al. (2000) also commented that women are more likely to be employed in secretarial and administrative posts, but not in professional roles within the construction sector. This reflects the under-representation of women in construction industry.

Ethnicity has also been identified as another factor affecting graduate employment in previous literature (Casplan and Gilham, 2005; Lim, 2010). Lim (2010) commented that Malay graduates are consistently less favourable in the labour market as compared to the non-Malay graduates in Malaysia. Lim's (2010) research found that Chinese graduates are found to have a lower probability of being unemployed and have on average 49 days less unemployment than Malay graduates. Casplan and Gilham's (2005) noted there is a marked difference between relatively high representation of minority ethnic groups on built environment courses in further and higher education and low representation in professional and managerial roles in these areas. Their study identified the structural and cultural characteristics that have prevented the minority ethnic professionals from following their career aims, and of the failure of the built environment industry more generally to be inclusive and diversify its workforce. The discussions and findings drew upon interviews with minority ethnic professionals, students, lecturers and employers working in Britain in construction, engineering, architecture, surveying, planning and urban and landscape design.

Age is another important factor affecting graduate employment (Artess et al., 2008; Devaney and Roberts, 2012; Smith et al., 2000; Urwin and Di Pietro, 2005). Smith et al. (2000) commented that men aged over 33 at graduation are 6 percentage points more likely to be unemployed or inactive than are men aged less than 24 at graduation. Smith et al. (2000) also commented that women who graduated aged between 24 and 33 are at least 2 percentage points more likely to be unemployed or inactive than younger female graduates.

English language ability has also been cited as one of the most important determinants for graduate employment (Dabalen et al., 2001; Lim, 2010). Lim (2010) commented that good English language proficiency gives an added advantage to university study, job application, and has a favourable impact on employment rates and reduces the number of days unemployed. It is definitely the case for countries that use English as a second language (Dabalen et al., 2001; Lan, 2003). In Malaysia, English is one of the official languages; the university changed the medium of instruction for science and mathematics courses in Malaysian public universities from Bahasa Melayu (the national language of Malaysia) to English in order to raise graduates' English standards.

\subsection{Concluding remarks and identification of research gap}

Characteristics, such as gender, ethnicity, age, English proficiency, all have various levels of effect on graduate employment (Artess et al., 2008; Dainty et al., 2000; Devaney and Roberts, 2012; Lim, 2010; Smith et al., 2000; Urwin and Di Pietro, 2005). On the other hand, only one previous study (Smith et al., 2000) stated that attendance type, which is full-time or part-time study, does not have an impact on graduate employment.

Previous studies did not compare if the level of the degree, i.e. undergraduate or postgraduate, had an impact on graduate employability as they mainly focused on studying either one type or another of the degrees. For example, Lim (2010), Smith et al. (2000) focused on studying undergraduate courses while Devaney and Roberts (2012) and Urwin and Di Pietro (2005) focused on investigating employability for graduates of postgraduate courses only. There is yet to have been a study of both undergraduate and postgraduate programmes and identifying whether the level of the degree has an impact on real estate and built environment graduates' employment outcomes. Mode of study, which is distance, on-campus or mixed mode study, has an impact on student satisfaction (Douglas et al., 2006), but there is as yet no previous literature to investigate its impact on graduate employment prospects. 
Devaney and Roberts (2012) conducted research on the employability of property and construction graduates in the UK. Their research aimed to identify the type of demographic backgrounds of built environment graduates who were more likely to gain employment. However, employment was defined in Devaney and Roberts's (2012) paper as any job, regardless of whether it was full-time or part-time. Furthermore, their research did not state clearly whether the targeted respondents in their research included only UK Permanent Residents or graduates from overseas countries as well. The inclusion of overseas graduates adds ambiguity to the analysis of graduate employment outcomes as they are subject to legal limitations on seeking employment in foreign countries. Moreover, Devaney and Roberts's (2012) research did not exclude the graduates who declared they were continuing on to further study. The inclusion of these students will cause bias of the result as they are unlikely to seek for employment after graduation.

Devaney and Roberts (2012) and Smith et al.'s (2000) studies used the UK government statistics on graduate employment. Dainty et al. (2000) and Urwin and Di Pietro's (2005) research used primary research data collected in the UK. Lim's (2010) respondents are graduates from undergraduate degree programmes from the Faculty of Business in the University of Utara Malaysia. There is not yet any research with an Australian focus using Australian official data for the research.

This research aims to fill this gap. The aim of this research is to identify a comprehensive picture of the characteristics influencing employment outcomes, which is whether the graduate gains employment or not, and employment patterns which is whether the graduate is employed on a full or part-time basis. This was done for real estate and built environment graduates who were Australian Permanent Residents only and had declared they were not continuing on to further study. This paper also benchmarks the characteristics affecting employment prospects of real estate graduates against those of built environment graduates. Characteristics considered in this paper include demographic characteristics, such as gender, age and whether speaking English at home, which is a proxy indicator of graduates' English proficiency and characteristics related to their study style, such as attendance type, mode of study and degree levels. This paper aims to address the following research questions in the Australian context:

- What are the differences in characteristics for real estate and other built environment graduates?

- What are the differences in the employment outcomes for real estate and built environment graduates who have different characteristics?

- What are the differences in the employment patterns for real estate and built environment graduates who have different characteristics?

\section{Research methods}

\subsection{Data source}

The data used in this paper have been collated from the Australian Graduate Survey (AGS) (AGS, 2015). AGS is a national census of newly-qualified higher education graduates that has been in operation since 1972. The survey is conducted approximately four months after the students have completed the requirements for their awards. The AGS sends its surveys to new graduates from all Australian universities, as well as a number of higher education institutes and colleges. The data used in this paper dates from 2010 to 2012.

Other similar studies conducted in the UK, such as Smith et al. (2000) and Devaney and Roberts (2012) also used the government statistics on graduate destination. Smith et al. (2000) used First Destination Survey (FDS), conducted by Careers Offices of each university and deposited with the Higher Education Statistics Agency (HESA) and Devaney and Roberts (2012) used HESA 
Destination of Leavers from Higher Education (DLHE) dataset. Davaney and Roberts (2012) used a four year long data (2005/06 to 2008/9) while Smith et al. (2000) has only used one year (1983) data. The current study used a similar type of government employment statistics for a three-year period.

\subsection{Validity and limitations of data}

Same as the use of graduates' statistics produced by the government, such as the FDS dataset by Smith et al. (2000) and the DLHE dataset by Davaney and Roberts (2012), the use of the AGS data is not without problems. The first problem is the incomplete response rate. The survey response rate for domestic graduates, which is the primary focus of the AGS, typically ranges from 60 to 65 per cent. There is no information on the response rate recorded for the graduates from overseas countries. As a measure to overcome this problem, this study only considers the employment outcomes for built environment graduates who are Australian Permanent Residents. Another reason for focusing on Australian Permanent Residents only is that overseas graduates have legal limitations in seeking employment in Australia and including them will potentially distort the results. The second problem is the time the survey was conducted. The graduates were invited to complete the survey only four months after the completion of their courses, and this may be too early to conclude their employment situation.

On the other hand, the main benefit of the AGS data is that, despite a less than complete response rate, it is the most comprehensive graduate survey in Australia and provides detailed information on a large enough sample of university graduates to produce a statistically sound data analysis. Furthermore, gaining employment within six months is a good indicator for measuring graduate labour market difficulties (McKnight, 1999). Based on McKnight's (1999) study on the 1995 UK graduates' employment destination, it indicated that graduates who remain unemployed after six months are typically unemployed for more than one year during the first three and a half years after finishing their degree. This compares with an average duration of unemployment of one month for graduates who were employed within six months of graduation. Unemployment at six months after graduation is also associated with a higher probability of being employed in a non-graduate occupation in the future (ibid.). Although the AGS survey is completed four months after the graduates finish their degree, it can still provide an indication of their employment prospects.

\subsection{Data preparation}

Dimensionality reduction was used to prepare the dataset for further analysis in this paper, from the raw data of AGS. R programming language was used to combine the three-year datasets of AGS data (2010-2012) into one dataset. Dimensionality reduction is the process of reducing the number of random variables under consideration. The reason to conduct dimensionality reduction in this paper was feature extraction. Feature extraction aims to transform data in the high-dimensional space to space of fewer dimensions. The data transformation within this project is linear, as in principal component analysis (PCA). In other words, the dimensionality reduction process of the AGS data within this paper reduces the number of columns in the dataset and replaces all of the columns in the data with a smaller number of columns that have a unique value for every row. In addition to dimensionality reduction, summary statistics were also used to produce a simpler classification of rows of data (Field et al., 2012).

Dimensionality reduction was used to produce categories for built environment courses. After reviewing the course titles provided under AGS classification and the written information about the Course Majors which graduates studied, the classification for built environment courses was produced including Architecture, Construction, Real Estate and Urban Design and Regional Planning. Real estate graduates included those who studied Real Estate and Valuation in the AGS study. In addition, the author also reviewed information contained in the columns, which states the 
graduates' Course Majors (up to four majors can be identified) and identifies the graduates who study built environment-related courses and included them into the respective groups together. If the graduates indicated that they were studying more than one course major, the author has grouped them according to information based on their Course Major One.

In total, there were 9206 built environment graduates in 2010-2012. Of them, 1258 studied Real Estate, 4156 studied Architecture, 2011 studied Construction and 2117 studied Urban Design and Regional Planning. Three hundred twenty-three built environment graduates studied double or triple majors with more than one built environment discipline, therefore, they have been counted in the individual courses which they studied. If the graduates studied double or triple majors, they are counted in all of the courses they studied but only once in the overall built environment category.

Dimensionality reduction was also used to produce the dataset for the degree levels and age classification of built environment graduates, i.e. below 24 or 24 or above. The reason for choosing 24 years old as a threshold was because the study included both undergraduate and postgraduate degree courses. The length of a Masters Degree in Australia is usually two years with graduates required to complete their survey about four months after graduation, so the majority of postgraduates would be at least 24 years old upon completion of their course.

The classification of degree levels are undergraduate and postgraduate levels. Undergraduate level includes the following courses: Advanced diploma or diploma, Bachelor degree (graduate entry), Bachelor degree (honours) and Bachelor degree (not honours or graduate entry) while postgraduate level include Graduate certificate, Graduate/Postgraduate diploma and Master degree by coursework. As this study focused on investigating the employment outcomes and patterns of graduates from taught degree courses only, the graduates who studied postgraduate research degree programmes were excluded in this study.

Although ethnicity has been mentioned as one of the key characteristics affecting graduate employment prospects in previous literature, it is not considered in this paper as the only ethnic information available in the AGS data was whether the graduate considered themselves an Aboriginal or Torres Strait Islander (ATSI). Because the number of ATSI students was very small, there were only 28 ATSI graduates out of 9206 built environment graduates who completed the AGS questionnaire from 2010 to 2012 , there is not enough data to make a sound analysis.

As mentioned in Section 3.2, this paper only includes the graduates who were Australian Permanent Residents. This paper also excludes the graduates who declared that they were continuing on to further study, as they were unlikely to seek full-time graduate level employment, in order to minimise the cause on the bias of results. After taking these into consideration, there were 991 real estate and 5909 built environment graduates considered in this study. Please see Table 1 for the detailed information of real estate and built environment graduates who were Australian Permanent Residents.

\section{INSERT TABLE 1 HERE}

\subsection{Data analysis}

Both descriptive and statistical analysis methods were used to assess the impact of characteristics on employment outcomes and patterns for real estate and built environment graduates. Descriptive statistical techniques were used to identify the employment outcomes and patterns of graduates having different characteristics. Pivot tables were used to sort, count and summarise all the AGS data related to real estate and built environment graduates employment, and then creates new 
tables to display the summarised data. R programming language was also used to conduct the statistical analysis of this research.

The next step was to identify the statistical significance of the influence of the characteristics on the employment outcomes and employment patterns of the real estate and built environment graduates. Chi-Squared Contingency 2-way analysis was used to conduct the data analysis in this research. The reason for using the 2-way analysis is to ensure the accuracy of the result. If the calculated value of the Chi-square test statistic is more than the critical value of 3.841 , which is equivalent to a 0.05 significance level, the null hypothesis is rejected. The critical value of 3.841 is used since it represents the critical value for a chi-square with 1 degree of freedom. The null hypothesis is that the two variables, i.e. characteristics and employment outcomes or employment patterns, are independent of each other. If the null hypothesis is rejected, it means that the two variables are not independent of each other (Field et al., 2012).

For the characteristics, such as gender, age, attendance type, degree level and speaking English at home or not, are binary variables. Despite some unknown answers for these categories, their sizes are insignificant and they are excluded in the analysis. For mode of study, only distance and oncampus modes were considered in the Chi-Squared Contingency 2-way analysis.

Validity is ensured for using Chi-Squared Contingency 2-way analysis as:

1. Both the independent and dependent variables are categorical

2. Data for the independent variables, i.e. the characteristics, are nominal and non-parametric

3. The sample size is at least 100

4. Only two categories in each variable. For mode of study, only consider answer for distance and on-campus

5. Random sample was used to collect data

6. The number of respondents in each cell should be at least 5

(Field et al., 2012)

The phi coefficient was used to measure the correlation between the employment outcomes and employment patterns against individual characteristics. The phi coefficient was chosen as it is designed for the comparison of truly dichotomous distributions, i.e., distributions that have only two points on their scale which indicate some unmeasurable attribute. The value of the phi correlation coefficient ranges from -1 to +1 , where $+/-1$ indicates perfect correlation between two variables and 0 indicates no relationship between two variables (Field et al., 2012).

\section{Research findings and discussions}

\subsection{Differences in characteristics for real estate and built environment graduates}

The real estate graduates were from a mixture of different backgrounds. About two-thirds of them $(68.01 \%)$ were males and nearly three-quarters of them $(70.64 \%)$ were mainly studying full-time. The dominant study mode was on-campus, $75.68 \%$ of real estate graduates were studying in this mode, and followed with distance learning (13.82\%) and mixed mode $(10.49 \%)$ respectively. The majority of real estate graduates studied undergraduate degree and were speaking English at home, their percentages were $74.27 \%$ and $88.90 \%$ respectively. The age distribution of real estate graduates was quite even, with $52.57 \%$ of graduates less than 24 years old.

As compared to real estate graduates, a higher percentage of built environment graduates studied full-time and on-campus and their percentages were $75.53 \%$ and $82.04 \%$ respectively. On the other hand, a lower percentage of built environment graduates studied at undergraduate level and were speaking English at home, their percentages are $60.60 \%$ and $83.45 \%$ respectively. Please see 
Table 2 for the information of the distribution of real estate and built environment graduates whose characteristics are different.

\section{INSERT TABLE 2}

\subsection{Differences in the employment outcomes for real estate and built environment graduates who have different characteristics}

Of the 991 real estate graduates who graduated in 2010-2012 who were Australian Permanent Residents and declared they were not continuing on to further study, there were $90.41 \%$ in employment at the time the AGS was conducted. The employment rate for real estate graduates is higher than the built environment graduates which is $88.41 \%$.

Speaking English at home, which is a rough indicator of English proficiency, has a statistically significant impact on employment outcomes for both real estate and built environment graduates, as their chi-square values were 14.492 and 101.3969 and their phi coefficient values were 0.13 , which indicated there were low positive relationships between the employment outcomes and English proficiency of these graduates (Jones, 2015). This finding shares Dabalen et al. (2001), Lan (2003) and Lim's (2010) conclusion on the significance of English proficiency on gaining graduate employment. Please see Tables 7 and 8 for the information on the statistical relationship between characteristics and employment outcomes.

The employment rate for real estate and built environment graduates who do not speak English at home are low. There were $11.00 \%$ and $16.08 \%$ of real estate and built environment graduates speaking a language other than English at home and their employment rates were $9.46 \%$ and $14.34 \%$ respectively (see Table 2 and Table 3 ). This makes the employment to population ratios for graduates speaking a language other than English at home as $77.98 \%$ and $78.84 \%$ respectively, as compared to the employment ratios for the real estate and built environment graduates speaking English at home as $91.94 \%$ and $90.29 \%$ (see Table 4).

Attendance type has a statistically significant impact on the employment outcomes for built environment graduates. The chi-square value was 38.0765 and the phi coefficient was -0.08 (see Tables 7 and 8). It means the built environment graduates who studied on a part-time basis were more likely to gain employment. The employment to population ratio for built environment graduates who studied on a part-time basis was $92.70 \%$, as compared to their counterparts who studied on a full-time basis at $87.03 \%$ (see Table 6). This is likely because these graduates were already working during their studies.

Mode of study, which is distance or on-campus mode, also has a statistically significant influence on the employment outcomes of built environment graduates as the chi-square value was 20.0886 and had a positive phi coefficient value of 0.06 . The built environment graduates who studied at distance mode are more likely to secure employment than those who studied on-campus. The employment to population ratios for the built environment was $94.04 \%$ as compared to the ratio of their counterparts who studied on-campus, which was $87.69 \%$ (see Table 6). There were $9.38 \%$ of built environment graduates studying at distance while only $4.57 \%$ were unemployed (see Table 2 and Table 3). A possible explanation is that the graduates who studied at distance mode were already employed whilst they studied for their degree course, therefore, they are more likely to still be employed after finishing their degree.

Gender, age and degree levels did not have statistically significant impact on the employment outcome for real estate and built environment graduates as their chi-square values are smaller than the critical value of 3.841 . 


\section{INSERT TABLE 3}

\section{INSERT TABLE 4}

\subsection{Differences in the employment patterns for real estate and built environment graduates who have different characteristics}

English proficiency has a statistically significant influence on employment patterns for real estate and built environment graduates as their chi-square values were 9.5107 and 21.6249 respectively. Their phi coefficient values were 0.11 and 0.07 , which indicated graduates with higher English proficiency were also more likely to secure full-time employment after graduation. The employment to population ratios on gaining a full-time job were $80.02 \%$ and $74.18 \%$ respectively (see Table 6 ), as compared to the ratios of the graduates who did not speak English at home of $57.80 \%$ and $59.05 \%$ respectively.

Age also has a statistically significant impact on the employment pattern of real estate and built environment graduates as their chi-square values were 6.3732 and 30.5038 respectively. Their phi coefficient values were -0.09 and -0.08 , which means graduates of age 24 or above are more likely to secure full-time employment after graduation but at a negligible level (Jones, 2015). The employment to population ratios for real estate and built environment graduates aged 24 or above who gained full-time employment were $81.06 \%$ and $74.36 \%$ respectively, as compared to the employment to population ratios for the graduates aged under 24 of $74.47 \%$ and $69.12 \%$ respectively (see Table 6). These findings contrast with Smith et al.'s (2000) view that younger graduates were more likely to be employed.

Attendance type has a statistically significant impact on employment patterns for real estate and built environment graduates as the chi-square values were 18.5825 and 45.146 and the phi coefficient values were -0.15 and -0.09 , which means the graduates who studied part-time were more likely to gain full-time employment after graduation. The employment to population ratios for real estate and built environment graduates who studied on a part-time basis and gaining full-time employment were $86.60 \%$ and $80.96 \%$ respectively, while the ratios for those who studied full-time and gained full-time employment were $73.86 \%$ and $68.74 \%$ (see Table 6).

Degree level has a statistically significant impact for the real estate graduates and its chi-square value was 10.06. The real estate graduates who studied a postgraduate degree are more likely to secure full-time employment, as the phi coefficient value was -0.11 . The employment to population ratios for real estate graduates who studied postgraduate degrees was $84.31 \%$ while the employment to population ratios for those who studied undergraduate degrees was $75.27 \%$.

Gender and mode of study have statistical significant impact on the employment patterns of built environment graduates only. The built environment graduates who studied at distance mode were more likely to secure full-time employment than those who studied on-campus, their employment to population ratios were $82.67 \%$ and $70.30 \%$.

Male built environment graduates were more likely to be in full-time employment than female graduates, with $64.59 \%$ and $35.39 \%$ of graduates employed on a full-time basis respectively (see Table 5). This is supported by the employment to population ratio, the ratios for males and females gaining full-time employment were $74.59 \%$ and $66.95 \%$ respectively (see Table 6 ). This finding is statistically significant as the chi-square value for gender and employment pattern for built environment graduates was 52.918 (see Table 7) and the phi coefficient value was 0.1 (see Table 8). This is aligned with the IER's (1997) finding, which was that male graduates were more likely to gain full-time employment. 
Female graduates were more likely to work in part-time roles than male graduates. The employment to population ratio for female built environment graduates working in part-time roles was $21.13 \%$ as compared to $14.01 \%$ of male graduates (see Table 6). This is in keeping with IER's (1997) finding, which was that females are more likely to work in part-time roles, although the percentage difference is getting smaller. In IER's (1997) study, it reported that $43 \%$ and $2 \%$ of female and male graduates worked in part-time roles. However, the difference in findings between the current and IER's (1997) study is separated by nearly 20 years and so demonstrates a significant shift.

Please see Table 9 for a summary of research findings.

\section{INSERT TABLE 5}

INSERT TABLE 6

\section{INSERT TABLE 7}

\section{INSERT TABLE 8}

\section{INSERT TABLE 9}

\section{Conclusion}

This paper investigated the characteristics influencing the employment outcomes and patterns of real estate and built environment graduates in Australia. This research also identified the differences of employment outcomes and patterns of those graduates. The characteristics identified in this paper included gender, age, attendance type, mode of study, degree level and English proficiency. This paper discussed the development of the dataset from the raw data of the Australian Graduate Survey (AGS) to identify the difference in the employment outcomes and patterns for the graduates.

There were 1258 real estate graduates and 9206 built environment graduates from 2010 to 2012 . Out of them, 991 real estate graduates (79\%) were Australian Permanent Residents and declared they were not continuing on to further study after graduation. 896 real estate graduates had secured employment when the Australian Graduate Survey was conducted, giving the employment rate of $90.41 \%$. There was a lower percentage of built environment graduates $(88.41 \%)$ who were Australian Permanent Residents and were not continuing on to further study who secured employment. There was a higher percentage of real estate graduates $(85.83 \%)$ than built environment graduates (81.09\%) employed in a full-time role. On the other hand, a higher percentage of built environment graduates worked part-time or were unemployed; their percentages were $18.91 \%$ and $11.59 \%$ respectively, as compared to $14.17 \%$ and $9.59 \%$ for real estate graduates.

English proficiency was an important factor for real estate and built environment graduates for gaining employment, the chi-square values and phi coefficient values validated this argument. On the other hand, gender, age and degree levels had no statistically significant impact on employment outcomes for real estate and built environment graduates. Overall, other characteristics are more likely to have an impact on the employment patterns for real estate and built environment graduates. English proficiency, age and attendance type had a significant impact on the employment patterns of real estate and built environment graduates, whilst degree level had a statistically significant impact on employment patterns for real estate graduates only, whereas gender and mode of study had a statistically significant impact on the employment patterns for built environment graduates. 
This paper identified some characteristics which universities can adopt to enhance employment prospects for real estate and built environment graduates. Speaking English at home, is an indicator for English proficiency and it has proved to be vital for gaining employment. In order to enhance graduates' English proficiency, universities can offer language courses or writing workshops to students. It is also important to include English proficiency, both speaking and writing, as part of the course learning outcomes in order to ensure students achieve a certain level of language competency before graduation. Furthermore, the universities can also change their courses' delivery style and student recruitment strategies in order to enhance the students' employment possibilities. Universities can consider offering more part-time and distance learning courses in order to further attract the employees who already work in the sector but without formal qualifications in real estate or built environment.

\section{References}

Artess, J., Ball, C. and Mok, P. (2008), Higher Degrees: Postgraduate Study in the UK 2000/01 to 2005/06, DIUS Research Report 08-16, Department for Innovation, Universities and Skills, London.

Australian Graduate Survey (AGS) (2015), Australian Graduate Survey. Available at http://www.graduatecareers.com.au/research/surveys/australiangraduatesurvey/ (last accessed: 25 May 2015).

Bradley, D., Noonan, P., Nugent, H. and Scales, B. (2008), Review of Australian Higher Education: Final report. Canberra, Australia.

Casplan, S. and Gilham, J. (2005), "Included against the odds: failure and success among minority ethnic built-environment professionals in Britain". Construction Management and Economics, Vol. 23, pp. 1007-1015.

Dabalen, A, Bankole, O. and Olatunde, A.A. (2001), "Labour market prospects for university graduates in Nigeria". Higher Education Policy, Vol. 14 No. 2, pp.141-159.

Dainty, A., Bagilhole, B. and Neale, R. (2000), "A grounded theory of women's career underachievement in large UK construction companies". Construction Management and Economics, Vol. 18, pp.239-250.

Department of Education, Science and Training (DEST), Australian Chamber of Commerce Industry (ACCl) and Business Council of Australia (BCA) (2002), Employability Skills for the Future. Canberra, Australia.

Department of Industry, Innovation, Climate Change, Science, Research and Tertiary Education (DIICCSRT) and Department of Education, Employment and Workplace Relations (DEEWR) (2013), Core Skills for Work Developmental Framework (CSfW), Canberra, Australia.

Devaney, S. and Roberts, D. (2012), "Who gets the jobs? Factors influencing the employability of property and construction graduates in the UK". Construction Management and Economics, Vol. 30, pp. 233-246.

Douglas, J., Douglas, A. and Barnes, B. (2006), "Measuring student satisfaction at a UK university", Quality Assurance in Education, Vol. 14 No. 3, pp. 251-267.

Elias, P., McKnight, A., Pitcher, J., Purcell, K. and Simm, C. (1999), Moving On: Graduate Careers Three Years after Graduation, Careers Service Unit/Department for Education and Employment, Manchester. 
Field, A., Miles, J. and Field, Z. (2012), Discovering Statistics Using R., Sage Publications Ltd., London.

Fielden, S. L. Davison, M.J., Gale, A. W. and Davey, C.L. (2000), "Women in construction: the untapped resource". Construction Management and Economics, Vol. 18, pp. 113-121.

IER (1997), Review of the Economy and Employment, Institute of Employment Research, HMSO, London.

Jones, L. (2015), Objective 3: Tests of association for nominal data. Available at http://www.angelo.edu/faculty/ljones/gov3301/block14/objective3.htm (last accessed: 26 May 2015).

Lan, P-C (2003), 'They have more money but I speak better English! Transnational encounters between Filipina domestics and Taiwanese employers'. Identities: Global Studies in Culture and Power, Vol. 10 No. 2, pp. 133-161.

Lim, H. (2010), "Predicting low employability graduates: The case of University Utara Malaysia". The Singapore Economic Review, Vol. 55 No. 3, pp. 523-535.

McKnight, A. (1999), "Graduate employability and performance indicators: first destination and beyond'; in Moving on: Graduate Careers Three Years After Graduation, CSU/ DfEE/ IER, Manchester.

PISG/ HEFCE Report February 99/11 (1999), Performance indicators in higher education. First Report on Performance Indicators Steering Group, HEFCE, Bristol.

Precision Consultancy (2007), Graduate Employability Skills Prepared for the Business, Industry and Higher Education Collaboration Council, Department of Education, Science and Training, Canberra, Australia.

Rae, D. (2007), 'Connecting enterprise and graduate employability. Challenges to the higher education culture and curriculum?'. Education and Training, Vol. 49 No. 8/9, pp. 605-619.

Smith, J., McKnight, A. and Naylor, R. (2000), "Graduate employability: policy and performance in higher education in the UK". Economic Journal, Vol.110 June, pp. F382-F411.

Urwin, P. and Di Pietro, G., (2005), "The impact of research and teaching quality inputs on the employment outcomes of postgraduates". Higher Education Quarterly, Vol. 59 No. 4, pp. 275-295. 